\title{
Dynamic Characterization of Rubber O-Rings: Squeeze and Size Effects
}

\author{
Farid Al-Bender, ${ }^{1}$ Federico Colombo, ${ }^{2}$ Dominiek Reynaerts, ${ }^{1}$ \\ Rodrigo Villavicencio, ${ }^{2}$ and Tobias Waumans ${ }^{3}$ \\ ${ }^{1}$ Division of Production Engineering, Machine Design and Automation, KU Leuven, Leuven, Belgium \\ ${ }^{2}$ Department of Mechanical and Aerospace Engineering, Politecnico di Torino, Torino, Italy \\ ${ }^{3}$ Leuven Air Bearings, KU Leuven, Leuven, Belgium \\ Correspondence should be addressed to Federico Colombo; federico.colombo@polito.it
}

Received 2 May 2017; Accepted 13 June 2017; Published 12 July 2017

Academic Editor: Michel Fillon

Copyright (C) 2017 Farid Al-Bender et al. This is an open access article distributed under the Creative Commons Attribution License, which permits unrestricted use, distribution, and reproduction in any medium, provided the original work is properly cited.

\begin{abstract}
This paper concerns the dynamic characterization of rubber O-rings used to introduce damping in high speed gas bearing systems. O-shaped rubber rings composed of high temperature rubber compounds are characterized in terms of stiffness and damping coefficients in the frequency range $100-800 \mathrm{~Hz}$. Simple formulas with frequency independent coefficients were identified to express the viscoelastic properties of the O-rings. The formulas proposed approximate the stiffness and damping coefficients of O-rings of general size.
\end{abstract}

\section{Introduction}

Air bearings at very high speeds can suffer the unstable whirl. A method to overcome this problem is to modify the bearings geometry and increase the stability threshold. An alternative method is to introduce external damping in the system by using a bush supported on rubber O-rings or other elastomeric material. The first experimental work in which the half-speed whirl was avoided by mounting the bushes flexibly goes back 50 years [1]. O-rings were used in gas bearings to improve the static stiffness [2], but in most cases their main function is to overcome the whirl instability in journal bearings $[3,4]$ or the pneumatic hammer [5]. In $[6,7]$ an analytical model is developed to predict the restoring and hysteresis characteristics of elastomer O-rings mounted in squeeze film dampers. Stiffness and damping coefficients of the elastic supports which ensure the stability of the rotor are theoretically studied in [8], where it is shown that it is possible to avoid the half-speed whirl. In order to select the support parameters in an optimal way, a stability study is performed in paper [9], in which design guidelines are given.

Literature shows that real viscoelastic materials have to be characterized by more than one relaxation time [12]. Anyway, for the sake of simplicity, a simple Kelvin Voigt model can be sufficiently accurate to predict the dynamic characteristics of rubber O-rings [13]. Finite element method can be used to predict characteristics of rubber rings in static conditions [14-16]. However, the experimental characterization of these O-rings is essential for predicting the threshold speed and calculating the rotor runout in case they are used as damping supports.

The stiffness and damping coefficients of these rubber elements depend on several parameters: temperature, amplitude and frequency of the excitation, preload, material, and size of the O-ring [17]. In [18] axial forces transmitted by O-rings subjected to a reciprocating drag were measured for various amplitudes and frequencies. Papers [10, 19] describe some test benches used to measure the viscoelastic properties of O-rings. In paper [20] a simplified approach for the proper selection of elastomers is proposed.

In a previous work [11] dynamic stiffness and damping coefficients of O-rings composed of NBR and Viton ${ }^{\circledR}$ materials were measured. Analogous O-ring properties were found in [3]. In the present paper O-rings composed of high temperature resistant rubber are tested with a test rig for the purpose developed in University of Leuven. The aim is 

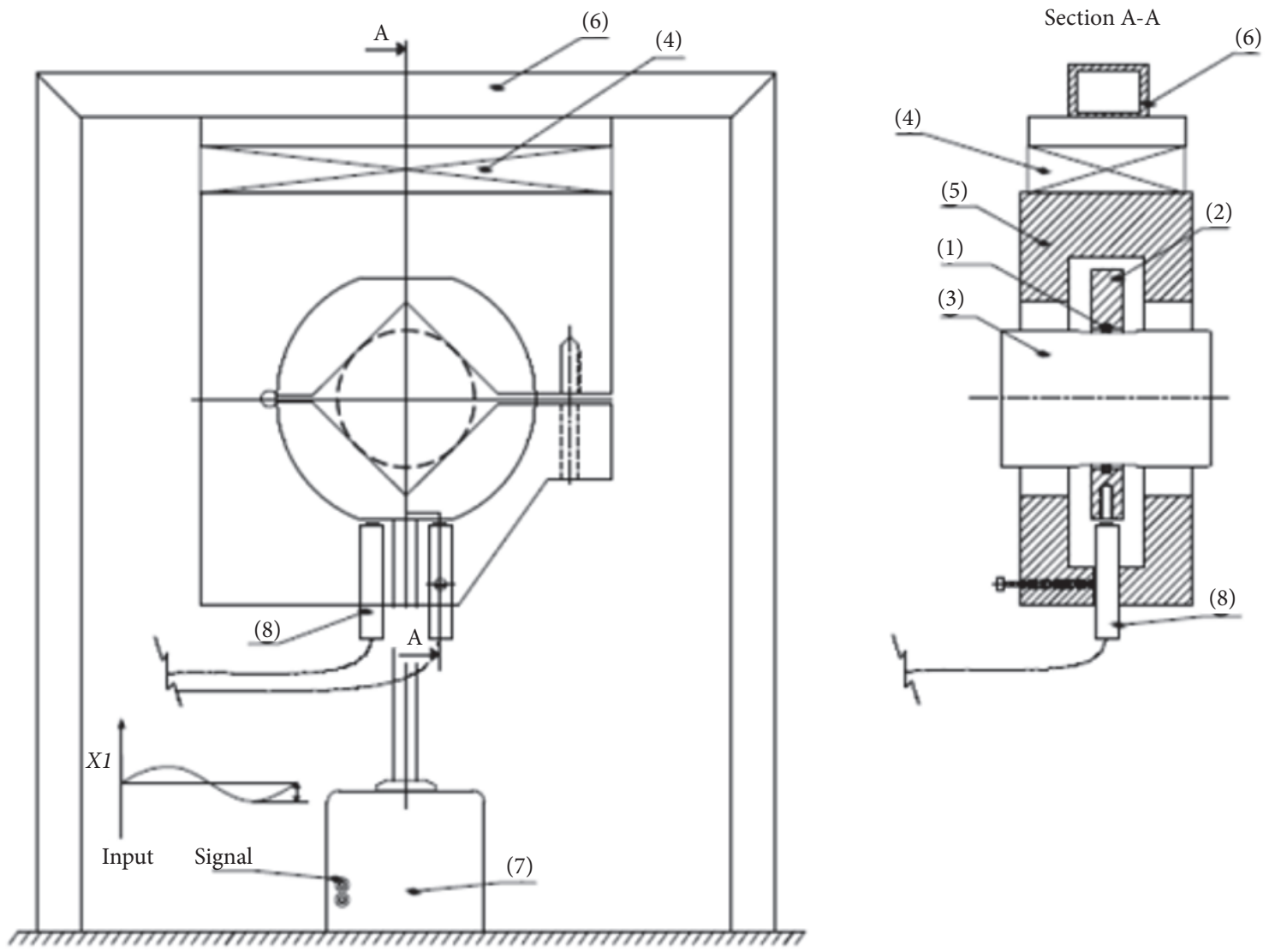

Figure 1: Test setup.

to identify stiffness and damping properties of O-rings of general size which could be used to study the stability of gas bearings, which are prone to whirl instability [21] or to pneumatic hammer instability. These coefficients could be inserted in lumped parameters models of gas bearings [2224 ] to evaluate their increased stability thanks to the use of the O-rings.

\section{Materials and Methods}

In literature two test methods can be found to measure the elastomer O-rings properties: the indirect method, named resonant mass method [17, 19], and the direct method.

In the first method (see [17]), the O-ring is compressed between a shaft, connected to the shaker base, and a bush, attached to a suspended mass. The displacements of the two elements that compress the O-ring are measured and no force transducers are needed.

The direct method, adopted in the present paper, consists in measuring directly the force transmitted by the O-ring. A test bench was set up as depicted in Figure 1. The O-ring under test (1) is compressed between bushing (2), connected to the stinger of shaker (7), and shaft (3), fixed to support (5). The load cell (4) is placed between support (5) and the fixed frame (6). By means of the shaker a sinusoidal displacement is imposed to the bushing. This displacement is detected by sensors (8), mounted on support (5). The signals from

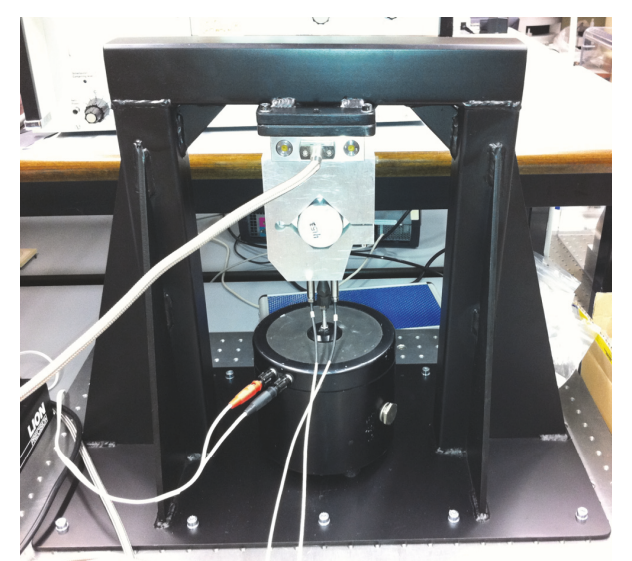

FIGURE 2: Photo of the test setup.

the load cell and the displacement transducers are sent to a DAQ system and then elaborated. Table 1 shows a list of the instrumentation used and Figure 2 shows a photo of the test bench.

The fixed frame was designed with FEM software to avoid resonance in the frequency range of the tests. The first natural frequency of the fixed frame is about $1.2 \mathrm{kHz}$, which is above the frequency range of tests. 
TABLE 1: List of instrumentation.

\begin{tabular}{lcc}
\hline Device & Model & Sensitivity, range \\
\hline Shaker & Type 4809, Brüel \& Kjær & $45 \mathrm{~N}, 10 \mathrm{~Hz}$ to $2 \mathrm{KHz}$, \\
& $736 \mathrm{~ms}^{-1}$ \\
Load cell & Type 9256C1, KISTLER & $13 \mathrm{pC} / \mathrm{N}, 250 \mathrm{~N}$ \\
$\begin{array}{l}\text { Displacement } \\
\text { transducer }\end{array}$ & $\begin{array}{c}\text { capaNCDT 600, } \\
\text { Micro-Epsilon }\end{array}$ & $20 \mathrm{~nm}-20 \mu \mathrm{m}$ \\
DAQ system & $\begin{array}{c}\text { PXI 1100, National } \\
\text { Instruments }\end{array}$ \\
\hline
\end{tabular}

The O-rings were compressed with a small excitation amplitude $(2.5 \mu \mathrm{m})$, so their behavior can be assumed to be linear. They were preloaded with various squeeze levels (5\%, $10 \%, 15 \%$, and $20 \%$ ). The squeeze is defined by

$$
S=\left(1-\frac{D_{i}-D_{e}}{2 \Phi}\right) \cdot 100,
$$

where $\Phi$ is the cross section diameter of the O-ring and $D_{i}$ and $D_{e}$ are the inside diameter of bushing (2) and the external diameter of shaft (3), respectively (see Figure 1).

2.1. O-Rings under Test. Rubber materials are used for different purposes, for example, vibration isolation, shock absorption, and sealing. Some compounds are designed for high temperatures, like Kalrez ${ }^{\circledR}$ and Viton. O-rings composed with such materials can be useful to increase the stability of high speed rotors supported by gas bearings. In literature it is difficult to find experimental data about O-rings of such compounds. For this reason, O-rings made in Viton, Kalrez 4079, and Kalrez 6375 were selected to be tested.

Viton is a fluoropolymer elastomer categorized under the ISO 1629 designation of FKM. Its density $\left(1800 \mathrm{~kg} / \mathrm{m}^{3}\right)$ is significantly higher than that of most types of rubber. It is used in a broad range of applications for its low cost. Compounds of Shore hardness of 75 and 90 were designated in this paper.

Kalrez is a perfluoroelastomer material (FFKM) with high chemical resistance; it has a temperature stability comparable with that of PTFE. It is mostly used in highly aggressive chemical processing, pharmaceutical, and aerospace applications. In particular, Kalrez 4079 is a carbon black filled compound with a maximum operating temperature of $315^{\circ} \mathrm{C}$. Kalrez 6375 has maximum operating temperature of $275^{\circ} \mathrm{C}$. Their Shore hardness is 75 .

Table 2 shows details of the $\mathrm{O}$-rings tested. The maximum temperature of the materials, the inner diameter $d$, and the cross section diameter $\Phi$ are indicated.

2.2. Test Procedure. In this section the procedure used to measure the dynamic stiffness of the O-rings is described. All tests were performed at constant ambient temperature of $20^{\circ} \mathrm{C}$. Each O-ring was tested at different frequencies by imposing the sinusoidal displacement $x$ (the input) and measuring the transmitted force $F$ (the output). For each frequency, the shaker amplitude was adjusted in open loop until displacement sensors indicated the required value (small displacement). On the base of the time functions $F(t)$ and
TABLE 2: Details of the O-rings under test.

\begin{tabular}{lccc}
\hline Material & Max. temp. $\left({ }^{\circ} \mathrm{C}\right)$ & $d(\mathrm{~mm})$ & $\Phi(\mathrm{mm})$ \\
\hline Kalrez 4079 & 316 & 11 & 1.78 \\
Kalrez 6375 & 275 & 11 & 1.78 \\
Viton 90 & 200 & 11 & 1.78 \\
& & 11 & 2.62 \\
Viton 90 & 200 & 41 & 1.78 \\
& & 41 & 2.62 \\
Viton 75 & 200 & 11 & 1.78 \\
& & 11 & 2.62 \\
Viton 75 & 200 & 41 & 1.78 \\
& & 41 & 2.62 \\
\hline
\end{tabular}

$x(t)$ acquired at several frequencies the experimental transfer functions $F(s) / x(s)$ were obtained. The transfer function is defined as ratio:

$$
T_{x F}(\omega)=\frac{P_{F x}(\omega)}{P_{x x}(\omega)},
$$

where $P_{F x}$ is the cross power spectral density of $x$ and $F$ and $P_{x x}$ is the power spectral density of $x$. Using a Kelvin Voigt model the transfer function can be written as follows:

$$
\frac{F(s)}{x(s)}=k+c s .
$$

Stiffness and damping coefficients were calculated with the following formulas:

$$
\begin{aligned}
& k(\omega)=\operatorname{Re}\left(\frac{F(j \omega)}{x(j \omega)}\right) \\
& c(\omega)=\frac{1}{\omega} \operatorname{Im}\left(\frac{F(j \omega)}{x(j \omega)}\right) .
\end{aligned}
$$

Finally, a least square procedure (see Appendix A) was adopted to find a best fit for the experimental data. This brought expressions for stiffness and damping in the exponential form

$$
\begin{aligned}
& k=A \omega^{\alpha}, \\
& c=B \omega^{\beta} .
\end{aligned}
$$

In these relations the pulsation is expressed in $\mathrm{rad} / \mathrm{s}$.

\section{Results and Discussion}

An example of Bode diagram is shown in Figure 3. It can be noticed that, approaching the resonance frequency of the test bench, the Bode diagram has a peak in the amplitude. Also the phase changes abruptly. For this reason, data at frequencies over $850 \mathrm{~Hz}$ are neglected.

3.1. Frequency Dependence. The results are summarized in Tables 3-5 for Viton 75, Viton 90, and Kalrez, respectively. They are presented in the form of coefficients $A, B, \alpha$, and $\beta$. 
TABLE 3: Summary of the results for Viton 75 O-ring.

\begin{tabular}{|c|c|c|c|c|c|c|c|c|}
\hline$d(\mathrm{~mm})$ & $\Phi(\mathrm{mm})$ & $S \%$ & $A \cdot 10^{6}$ & $\alpha$ & $k 200(\mathrm{MN} / \mathrm{m})$ & $B \cdot 10^{6}$ & $\beta$ & $c 200(\mathrm{Ns} / \mathrm{m})$ \\
\hline \multirow{4}{*}{11} & \multirow{4}{*}{1,78} & 5 & 0,0347 & 0,331 & 0,368 & 0,0293 & $-0,666$ & 253 \\
\hline & & 10 & 0,131 & 0,268 & 0,887 & 0,0298 & $-0,508$ & 794 \\
\hline & & 15 & 0,0666 & 0,384 & 1,032 & 0,0335 & $-0,544$ & 690 \\
\hline & & 20 & 0,155 & 0,295 & 1,272 & 0,094 & $-0,66$ & 847 \\
\hline \multirow{3}{*}{11} & \multirow{3}{*}{2,62} & 10 & 0,275 & 0,192 & 1,082 & 0,469 & $-0,923$ & 647 \\
\hline & & 15 & 0,111 & 0,384 & 1,720 & 0,177 & $-0,673$ & 1453 \\
\hline & & 20 & 0,08 & 0,492 & 2,679 & 0,369 & $-0,735$ & 1946 \\
\hline \multirow{4}{*}{41} & \multirow{4}{*}{1,78} & 5 & 0,1644 & 0,474 & 4,8402 & 0,0328 & $-0,297$ & 3940 \\
\hline & & 10 & 0,1811 & 0,463 & 4,9298 & 0,0389 & $-0,311$ & 4228 \\
\hline & & 15 & 0,0550 & 0,631 & 4,9655 & 0,0320 & $-0,278$ & 4405 \\
\hline & & 20 & 0,1378 & 0,542 & 6,5927 & 0,0370 & $-0,273$ & 5278 \\
\hline \multirow{4}{*}{41} & \multirow{4}{*}{2,62} & 5 & 0,0791 & 0,51 & 3,0100 & 0,0115 & $-0,209$ & 2584 \\
\hline & & 10 & 0,0903 & 0,555 & 4,7403 & 0,0223 & $-0,254$ & 3647 \\
\hline & & 15 & 0,0958 & 0,56 & 5,2100 & 0,0286 & $-0,27$ & 4164 \\
\hline & & 20 & 0,1427 & 0,541 & 6,7758 & 0,0408 & $-0,291$ & 5112 \\
\hline
\end{tabular}

TABLE 4: Summary of the results for Viton 90 O-ring.

\begin{tabular}{|c|c|c|c|c|c|c|c|c|}
\hline$d(\mathrm{~mm})$ & $\Phi(\mathrm{mm})$ & $S \%$ & $A \cdot 10^{6}$ & $\alpha$ & $k 200(\mathrm{MN} / \mathrm{m})$ & $B \cdot 10^{6}$ & $\beta$ & $c 200(\mathrm{Ns} / \mathrm{m})$ \\
\hline \multirow{4}{*}{11} & \multirow{4}{*}{1,78} & 5 & 0,229 & 0,132 & 0,588 & 0,654 & $-1,006$ & 499 \\
\hline & & 10 & 0,504 & 0,218 & 2,386 & 0,620 & $-0,917$ & 892 \\
\hline & & 15 & 0,125 & 0,379 & 1,861 & 0,058 & $-0,557$ & 1082 \\
\hline & & 20 & 1,380 & 0,160 & 4,323 & 0,069 & $-0,462$ & 2568 \\
\hline \multirow{3}{*}{11} & \multirow{3}{*}{2,62} & 10 & 1,428 & 0,114 & 3,221 & 0,460 & $-0,828$ & 1249 \\
\hline & & 15 & 5,602 & 0,072 & 9,385 & 22,750 & $-1,364$ & 1348 \\
\hline & & 20 & 0,472 & 0,416 & 9,188 & 11,280 & $-1,122$ & 3758 \\
\hline \multirow{4}{*}{41} & \multirow{4}{*}{1,78} & 5 & 0,0994 & 0,597 & 7,039 & 0,028 & $-0,245$ & 4868 \\
\hline & & 10 & 0,116 & 0,617 & 9,485 & 0,050 & $-0,296$ & 6048 \\
\hline & & 15 & 0,284 & 0,521 & 11,691 & 0,090 & $-0,333$ & 8404 \\
\hline & & 20 & 0,164 & 0,625 & 14,204 & 0,195 & $-0,443$ & 8249 \\
\hline \multirow{4}{*}{41} & \multirow{4}{*}{2,62} & 5 & 0,329 & 0,487 & 10,637 & 0,093 & $-0,390$ & 5750 \\
\hline & & 10 & 0,362 & 0,528 & 15,666 & 0,158 & $-0,421$ & 7823 \\
\hline & & 15 & 0,421 & 0,492 & 14,083 & 0,218 & $-0,463$ & 8001 \\
\hline & & 20 & 0,740 & 0,467 & 20,715 & 0,171 & $-0,387$ & 10810 \\
\hline
\end{tabular}

TABLE 5: Summary of the results for Kalrez O-ring $(d=11 \mathrm{~mm}, \Phi=1.78 \mathrm{~mm})$.

\begin{tabular}{|c|c|c|c|c|c|c|c|}
\hline Material & $S \%$ & $A \cdot 10^{6}$ & $\alpha$ & $k 200(\mathrm{MN} / \mathrm{m})$ & $B \cdot 10^{6}$ & $\beta$ & $c 200(\mathrm{Ns} / \mathrm{m})$ \\
\hline \multirow{4}{*}{ Kalrez 4079} & 5 & \multicolumn{6}{|c|}{ n.a. } \\
\hline & 10 & 0,080 & 0,409 & 1,481 & 0,0776 & $-0,580$ & 1237 \\
\hline & 15 & 0,214 & 0,314 & 2,012 & 0,193 & $-0,675$ & 1562 \\
\hline & 20 & 0,168 & 0,391 & 2,736 & 0,211 & $-0,654$ & 1983 \\
\hline \multirow{4}{*}{ Kalrez 6375} & 5 & 0,0312 & 0,429 & 0,666 & 0,0370 & $-0,564$ & 661 \\
\hline & 10 & 0,0266 & 0,514 & 1,042 & 0,0877 & $-0,637$ & 931 \\
\hline & 15 & 0,0371 & 0,512 & 1,433 & 0,284 & $-0,778$ & 1102 \\
\hline & 20 & 0,0983 & 0,377 & 1,449 & 0,0478 & $-0,501$ & 1339 \\
\hline
\end{tabular}



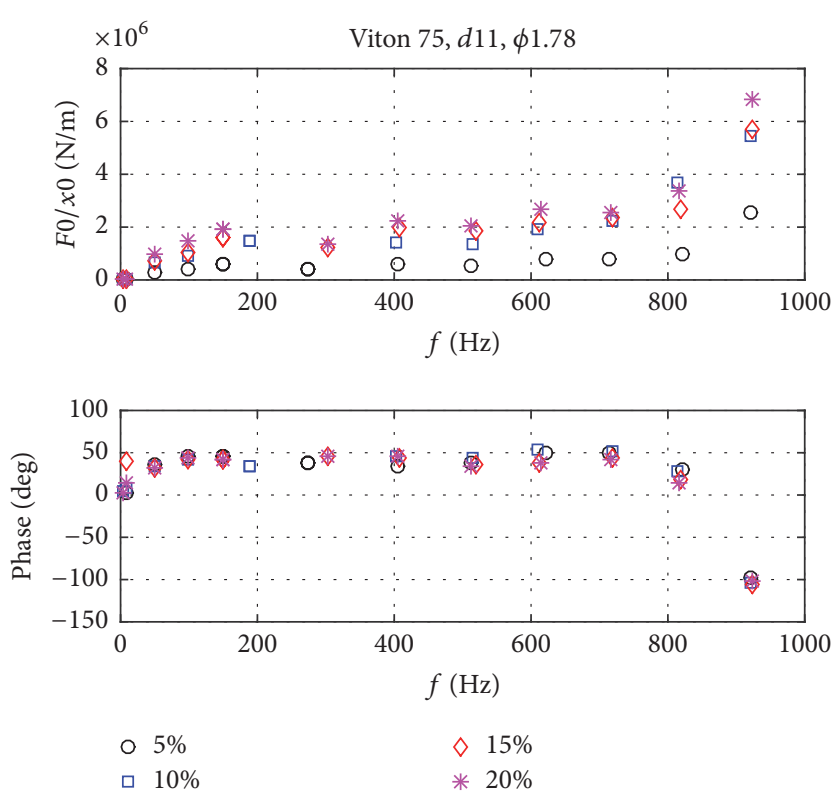

Figure 3: Body diagram of transfer function $F(s) / x(s)$ in case of Viton $75, d=11 \mathrm{~mm}, \Phi=1.78 \mathrm{~mm}$.

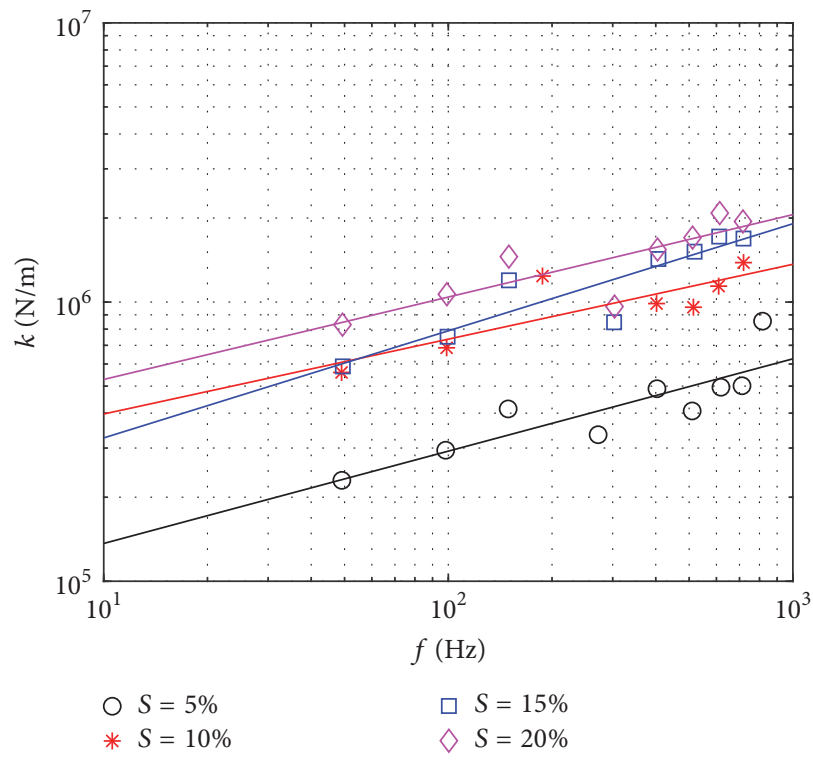

(a) Effect of squeeze $S$ on stiffness $k$ of Viton 75 O-rings, $d=11 \mathrm{~mm}$, $\Phi=1.78 \mathrm{~mm}$

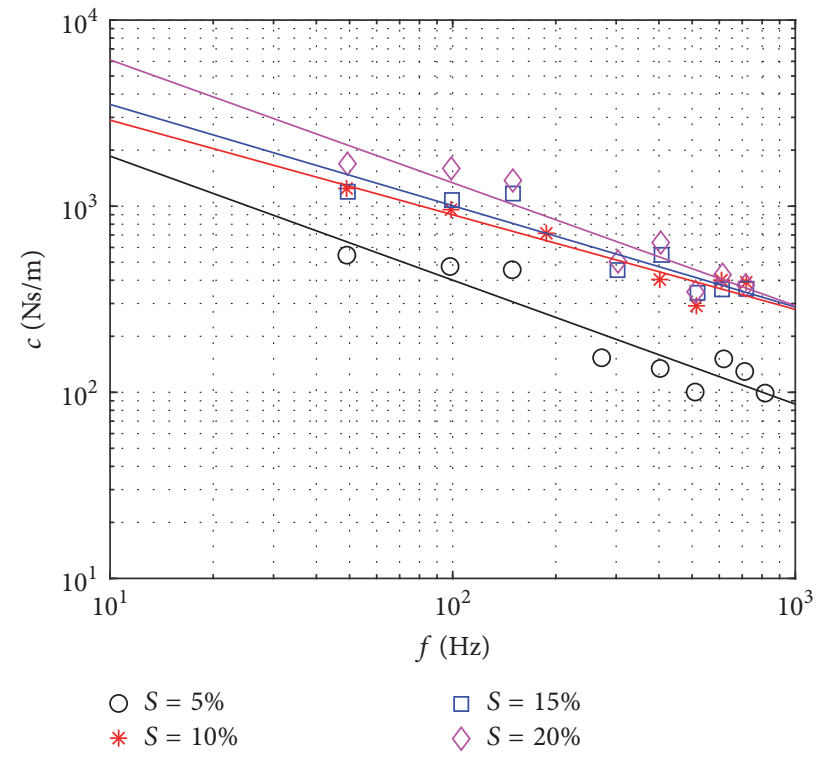

(b) Effect of squeeze $S$ on damping $c$ of Viton 75 O-rings, $d=11 \mathrm{~mm}$, $\Phi=1.78 \mathrm{~mm}$

FIGURE 4

Stiffness and damping coefficients at a frequency of $200 \mathrm{~Hz}$ are also given in the tables. These are more representative than the previous coefficients as they are less affected by measuring errors.

In Figures 4-7, the experimental points of stiffness and damping coefficients are plotted with the fitted power law lines.

Figures 4-7 show the squeeze effect on $k$ and $c$ coefficients for a selected size of the $\mathrm{O}$-ring and the size influence on $k$ and $c$ at a medium squeeze level (15\%).
Figure 4(a) shows the effect of squeeze on the stiffness coefficient of Viton 75 O-rings of size $d=11 \mathrm{~mm}, \Phi=$ $1.78 \mathrm{~mm}$. It can be seen that stiffness increases with frequency and with the squeeze level.

Figure 4(b) shows the effect of squeeze on the damping coefficient of Viton 75 O-rings of size $d=11 \mathrm{~mm}, \Phi=$ $1.78 \mathrm{~mm}$. Damping decreases with frequency and increases with the squeeze level.

Figures 5(a) and 5(b) show the influence of the size on the stiffness and damping coefficients at a $15 \%$ squeeze 


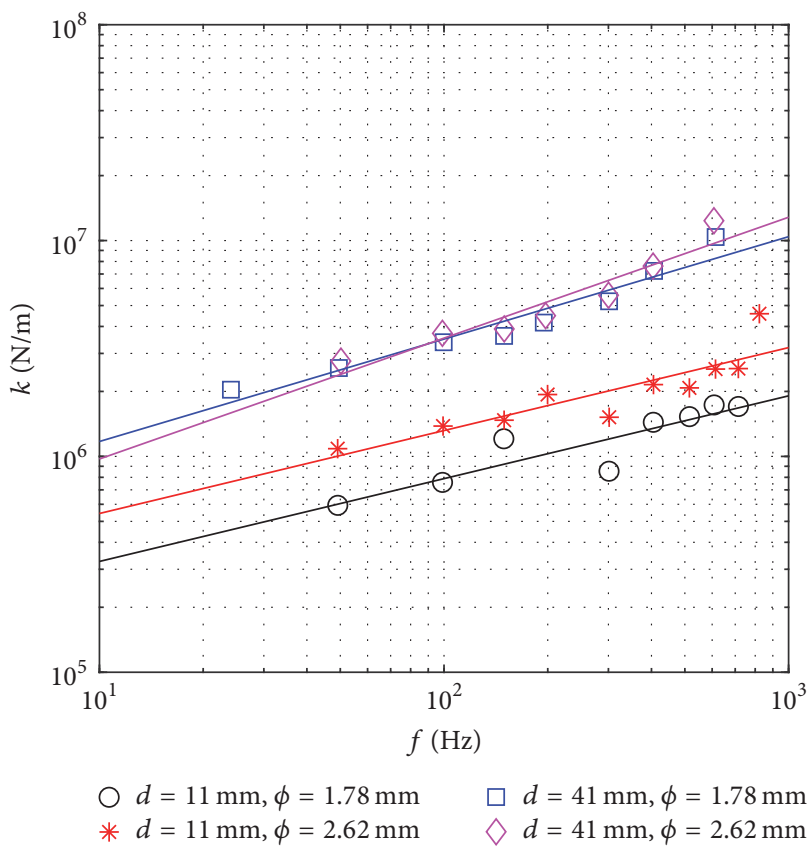

(a) Effect of size on stiffness $k$ of Viton 75 O-rings, squeeze level 15\%

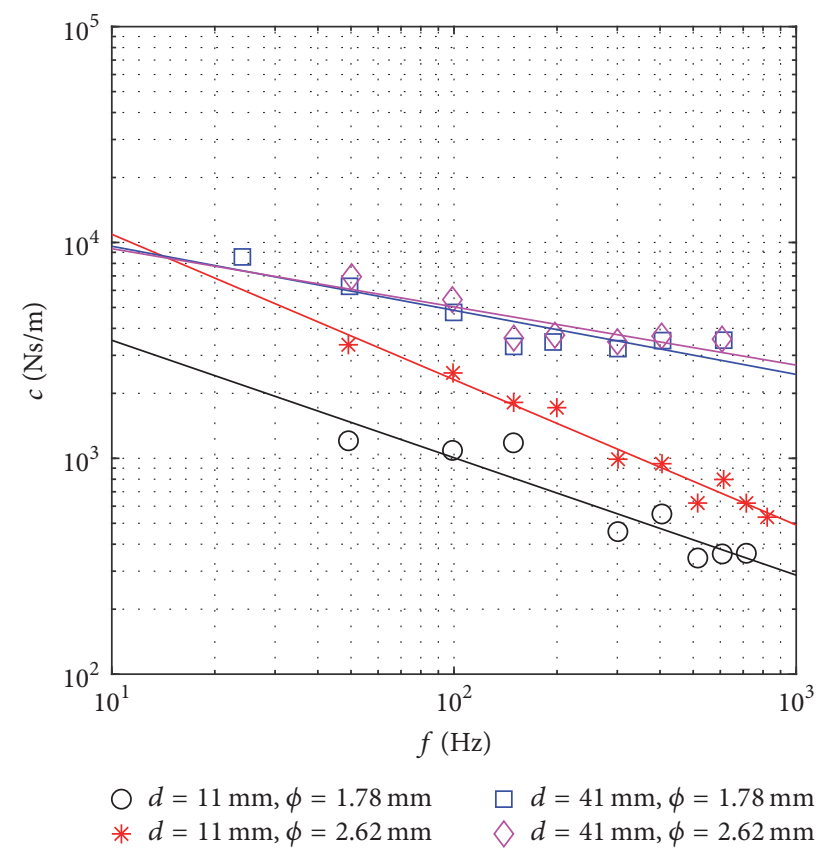

(b) Effect of size on damping $c$ of Viton 75 O-rings, squeeze level 15\%

Figure 5

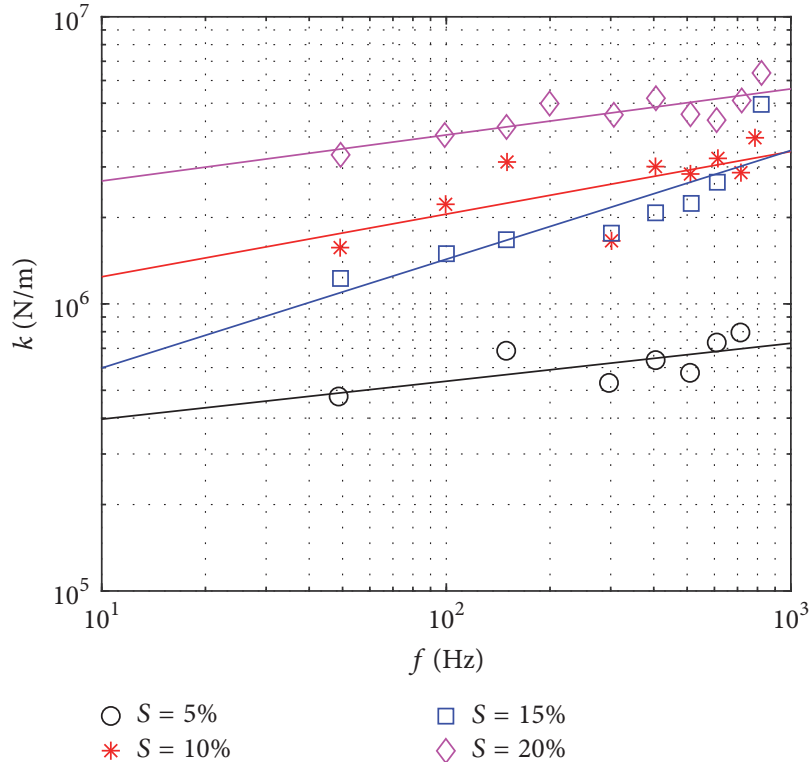

(a) Effect of squeeze $S$ on stiffness $k$ of Viton 90 O-rings, $d=11 \mathrm{~mm}$, $\Phi=1.78 \mathrm{~mm}$

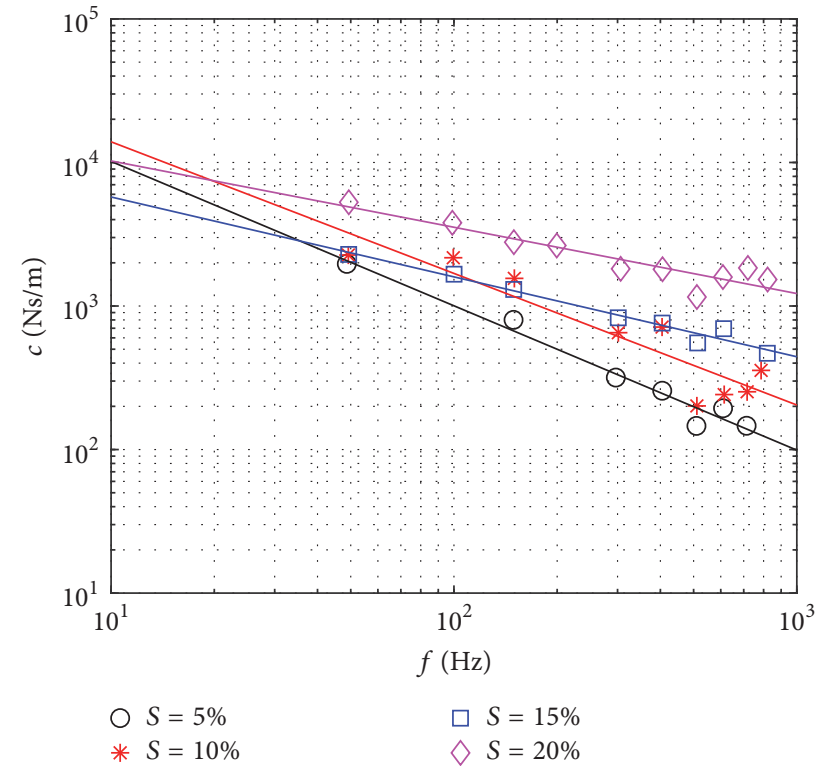

(b) Effect of squeeze $S$ on damping $c$ of Viton 90 O-rings, $d=11 \mathrm{~mm}$, $\Phi=1.78 \mathrm{~mm}$

Figure 6

level. Stiffness and damping coefficients increase both with diameter $d$ and cross diameter $\Phi$, although the influence of $\Phi$ is almost negligible when $d$ is high. This is in accordance with data of paper [10], in which the influence of the cross section diameter is negligible with an O-ring of internal diameter $d$ of about $73 \mathrm{~mm}$.
Figures 6(a) and 6(b) show the effect of squeeze on stiffness and damping coefficients of Viton 90 O-rings of size $d=11 \mathrm{~mm}, \Phi=1.78 \mathrm{~mm}$. It can be noticed that Viton 90 is more rigid and has also a greater damping capability.

Similar trends are shown in Figures $7(\mathrm{a})$ and $7(\mathrm{~b})$ presenting the influence of the size on the stiffness and damping 


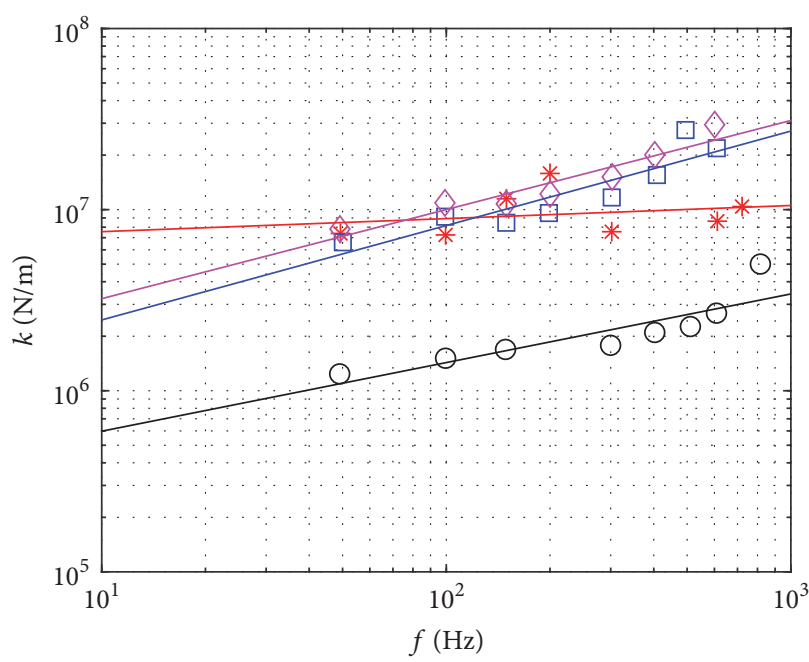

$\begin{aligned} \bigcirc d=11 \mathrm{~mm}, \phi=1.78 \mathrm{~mm} & \square d=41 \mathrm{~mm}, \phi=1.78 \mathrm{~mm} \\ * d=11 \mathrm{~mm}, \phi=2.62 \mathrm{~mm} & \quad \downarrow d=41 \mathrm{~mm}, \phi=2.62 \mathrm{~mm}\end{aligned}$

(a) Effect of size on stiffness $k$ of Viton 90 O-rings, squeeze level 15\%

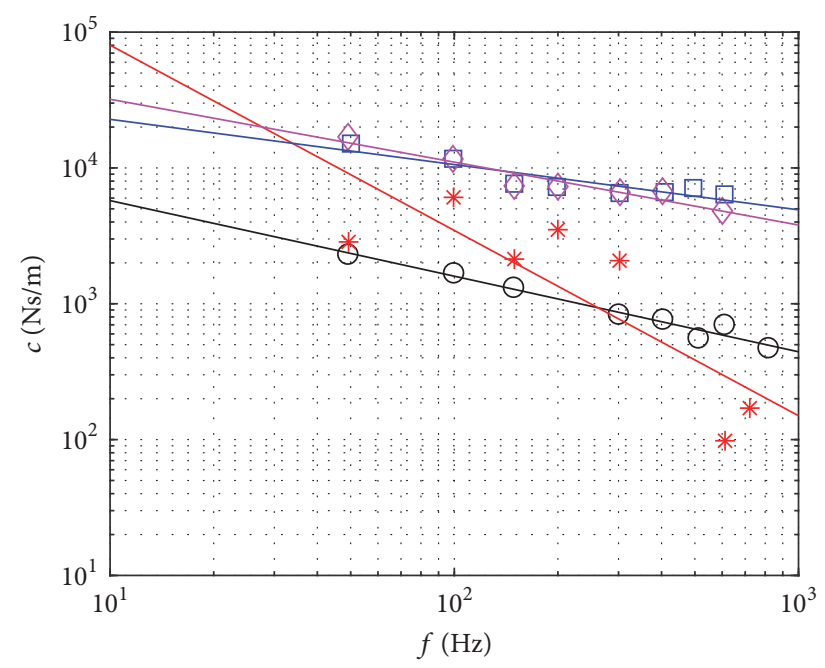

$\begin{array}{rlrl}\bigcirc d & =11 \mathrm{~mm}, \phi=1.78 \mathrm{~mm} & \square d & =41 \mathrm{~mm}, \phi=1.78 \mathrm{~mm} \\ * d=11 \mathrm{~mm}, \phi=2.62 \mathrm{~mm} & \nabla d=41 \mathrm{~mm}, \phi=2.62 \mathrm{~mm}\end{array}$

(b) Effect of size on damping $c$ of Viton 90 O-rings, squeeze level 15\%

FIGURE 7

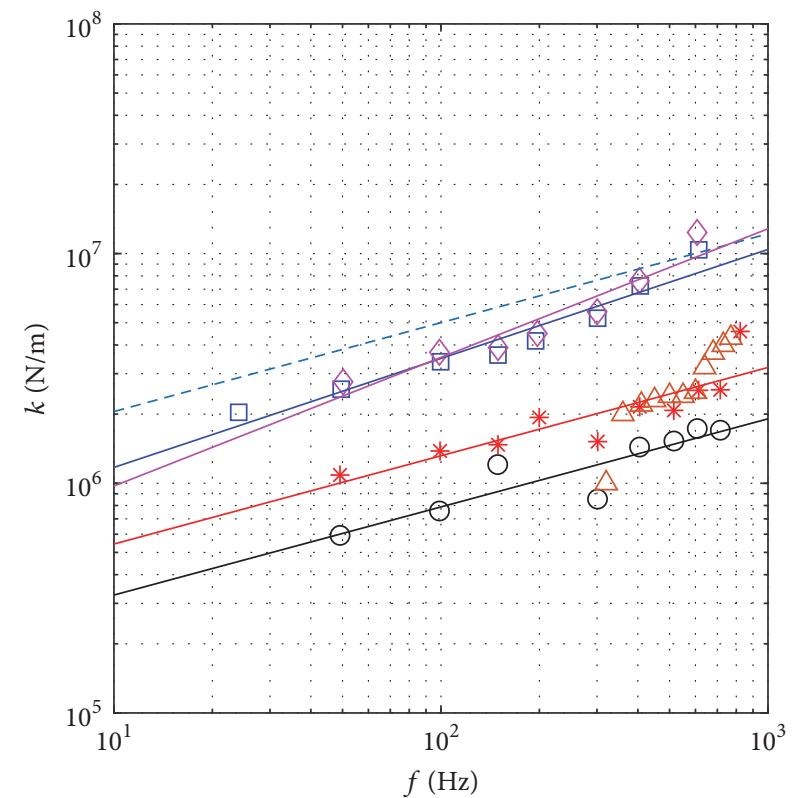

$\mathrm{O} d=11 \mathrm{~mm}, \phi=1.78 \mathrm{~mm}$

* $d=11 \mathrm{~mm}, \phi=2.62 \mathrm{~mm}$

$\square d=41 \mathrm{~mm}, \phi=1.78 \mathrm{~mm}$

$\diamond d=41 \mathrm{~mm}, \phi=2.62 \mathrm{~mm}$

- - From [13]

$\triangle$ From [15]

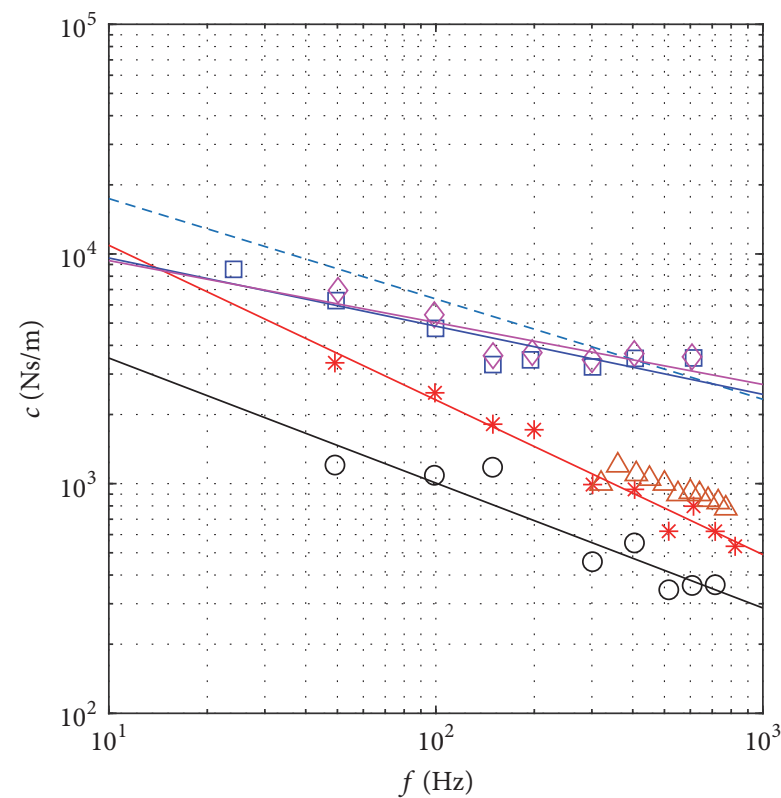

$\bigcirc d=11 \mathrm{~mm}, \phi=1.78 \mathrm{~mm}$

* $d=11 \mathrm{~mm}, \phi=2.62 \mathrm{~mm}$

$\square d=41 \mathrm{~mm}, \phi=1.78 \mathrm{~mm}$ $\diamond \quad d=41 \mathrm{~mm}, \phi=2.62 \mathrm{~mm}$

- - From [13]

$\triangle$ From [15]

Figure 8: Comparison of the results of Viton 75, squeeze level 15\%, with those from [10, 11].

coefficients at a $15 \%$ squeeze level for Viton 90 O-rings. Both stiffness and damping are greater in Viton 90 with respect to Viton 70.

Literature data on these coefficients are very difficult to be found. Table 6 shows details about O-rings from $[10,11]$ tested with the mass resonant method. Figure 8 compares these results with that of the present paper, with Viton material and a squeeze level of $15 \%$. Considering that stiffness and damping should increase with the Shore hardness and with both $d$ and $\Phi$, coefficients from [11] are compatible with that of $d=41 \mathrm{~mm}$, as their Shore hardness and their cross section diameter are lower. Furthermore the coefficients from [10] are greater than that of $d=41 \mathrm{~mm}$ and squeeze $15 \%$ and also this comparison is good. 


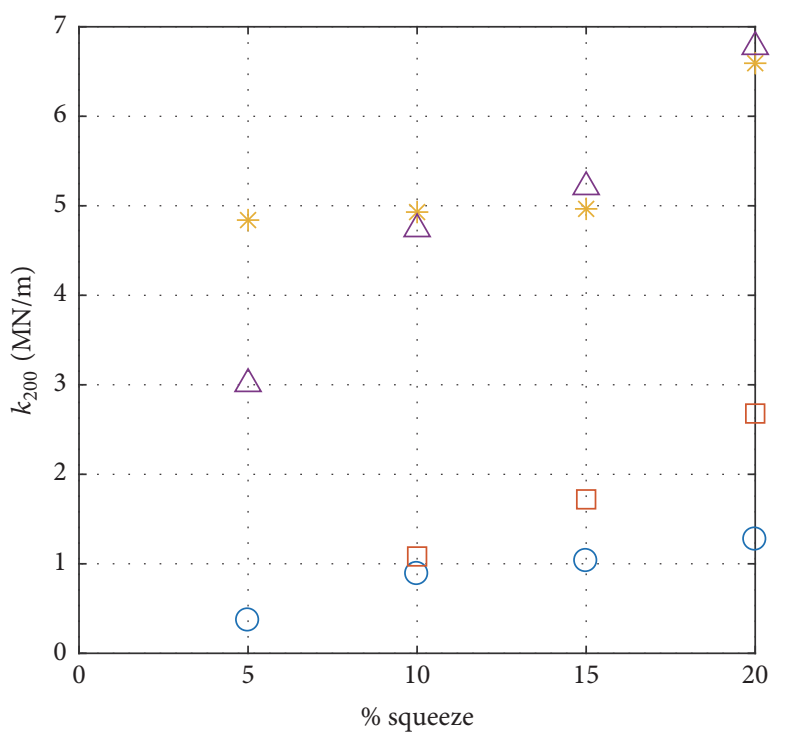

d $d=11 \mathrm{~mm}, \phi=1.78 \mathrm{~mm} \quad * \quad d=41 \mathrm{~mm}, \phi=1.78 \mathrm{~mm}$

$\square d=11 \mathrm{~mm}, \phi=2.62 \mathrm{~mm} \triangle d=41 \mathrm{~mm}, \phi=2.62 \mathrm{~mm}$

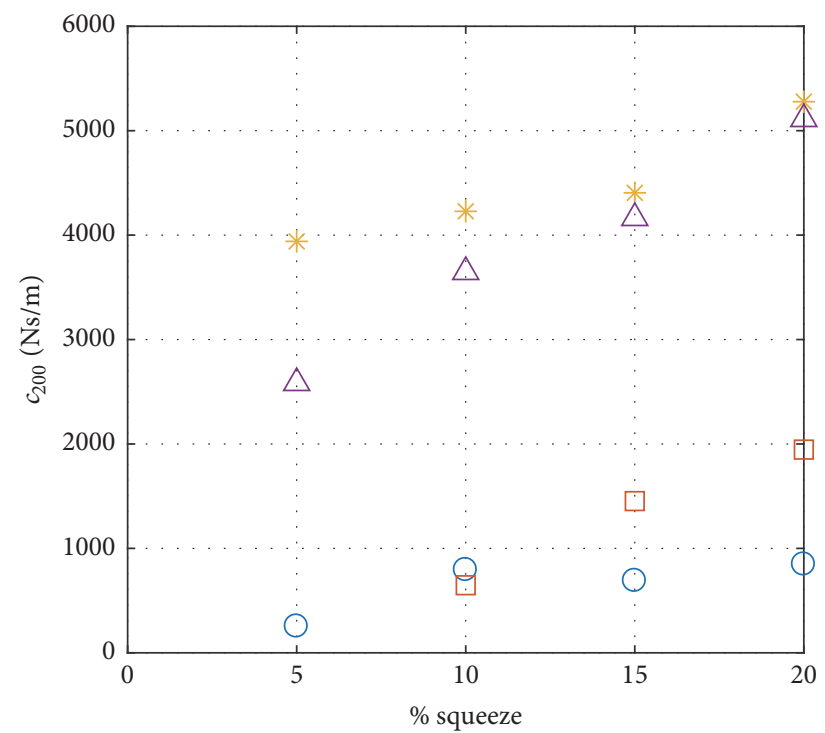

$d=11 \mathrm{~mm}, \phi=1.78 \mathrm{~mm} \quad * \quad d=41 \mathrm{~mm}, \phi=1.78 \mathrm{~mm}$

$\square d=11 \mathrm{~mm}, \phi=2.62 \mathrm{~mm} \triangle d=41 \mathrm{~mm}, \phi=2.62 \mathrm{~mm}$

FIGURE 9: $k_{200}$ and $c_{200}$ versus $S$ for Viton 75.
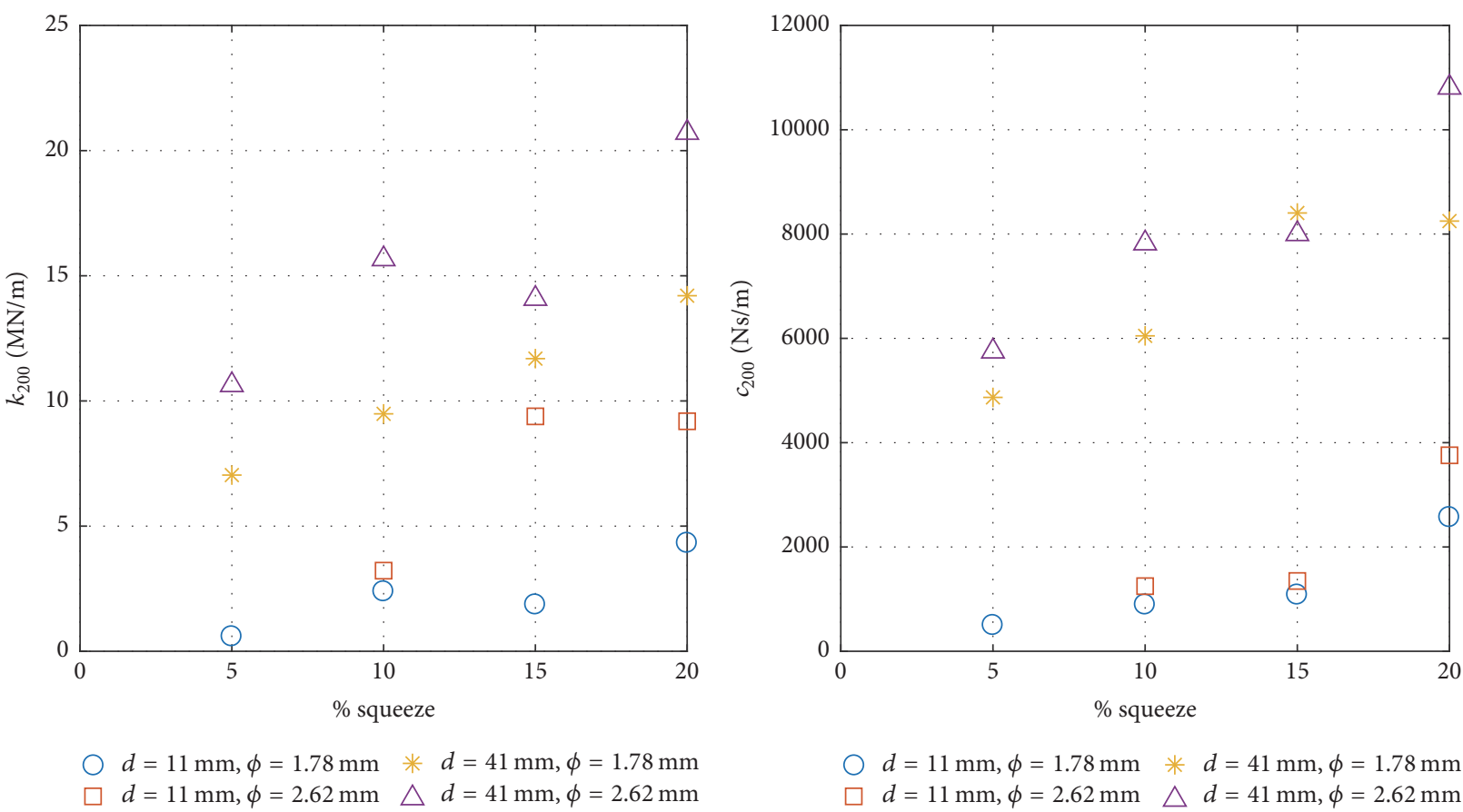

Figure 10: $k_{200}$ and $c_{200}$ versus $S$ for Viton 90.

Considering that the sensitivity of rubber properties on temperature is very high, the discrepancies on the data from different test benches are acceptable. Also, as noticed in [19], the O-rings can easily be twisted during mounting and this fact could influence the test results. To avoid this problem the O-rings could be lubricated, but the presence of a lubricant could be another source of uncertainty.
3.2. Dependence on the Squeeze. The relationship between the stiffness and damping coefficients and the squeeze $S$ is approximately linear. Figures 9 to 11 show the coefficients at frequency of $200 \mathrm{~Hz}$.

3.3. Dependence on O-Ring Size. The effects of the inner diameter $d$ and of the cross section diameter $\Phi$ can be 

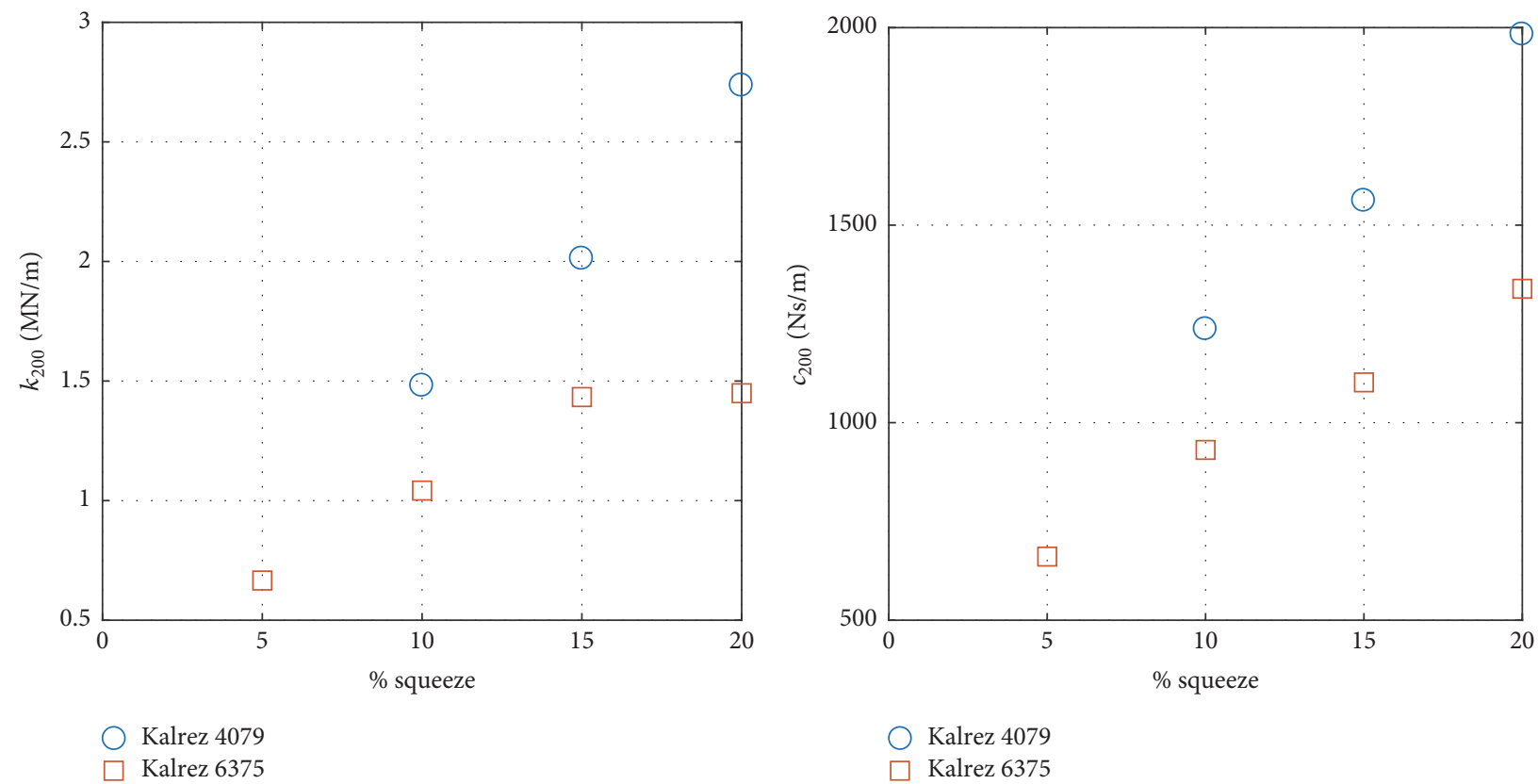

FIGURE 11: $k_{200}$ and $c_{200}$ versus $S$ for Kalrez O-rings.

TABLE 6: Dimensions of the O-rings tested in $[10,11]$.

\begin{tabular}{rcccc}
\hline Rubber & $\Phi(\mathrm{mm})$ & $d(\mathrm{~mm})$ & Squeeze level & Temperature \\
\hline Ref. [10] Viton 70 & 3.53 & 69 & $15 \%$ & $21^{\circ} \mathrm{C}$ \\
Ref. [11] Viton 70 & 1.73 & 41 & $28 \%$ & n.a. \\
\hline
\end{tabular}

evaluated plotting the coefficients obtained with the following ratios:

$$
\begin{aligned}
& \bar{k}_{200}=\frac{k_{200}}{d \cdot \Phi}, \\
& \bar{c}_{200}=\frac{c_{200}}{d \cdot \Phi} .
\end{aligned}
$$

The results are depicted in Figures 12 and 13. In first approximation it is possible to collapse the four trends into one curve. In this way the properties of the O-rings can be identified independently of their size:

$$
\begin{aligned}
& \bar{k}_{200}=C+\gamma S \\
& \bar{c}_{200}=D+\delta S .
\end{aligned}
$$

The least squares procedure was adopted to fit the linear trends to experimental data (see Appendix B). In these equations the squeeze is expressed in percentage form $(S=5$, 10,15 , and 20). Table 7 summarizes the results.

\section{Conclusions}

In the present work the dynamic properties of rubber O-rings are provided. The following conclusions can be made:

(i) Stiffness increases with frequency, while damping decreases.
TABLE 7: Coefficients for the identification of $\bar{k}_{200}$ and $\bar{c}_{200}$.

\begin{tabular}{lcccc}
\hline Rubber & $C\left(\mathrm{MN} / \mathrm{m}^{3}\right)$ & $\gamma\left(\mathrm{MN} / \mathrm{m}^{3}\right)$ & $D\left(\mathrm{Ns} / \mathrm{m}^{3}\right)$ & $\delta\left(\mathrm{Ns} / \mathrm{m}^{3}\right)$ \\
\hline Viton 75 & 22595 & 2610 & $2.069 \cdot 10^{7}$ & $1.800 \cdot 10^{6}$ \\
Viton 90 & 22915 & 10412 & $1.177 \cdot 10^{7}$ & $0.457 \cdot 10^{7}$ \\
\hline
\end{tabular}

(ii) Stiffness and damping coefficients increase both with the size of the O-ring (internal diameter $d$ and crosssectional diameter $\Phi$ ) and with the squeeze level.

(iii) A material with higher Shore hardness has higher stiffness and damping.

Formulas are provided to identify as a first approximation the stiffness and damping coefficients of O-rings of general size. These formulas can be inserted in lumped parameters models of gas bearings to evaluate their increased stability with the use of the O-rings.

Future interesting investigations could concern the verification of these formulas with O-rings of different size. Also the effect of temperature could be taken into account setting up a temperature control.

\section{Appendix}

\section{A. Interpolating Coefficients}

Coefficients $A$ and $\alpha$ are calculated solving the following linear system by least squares procedure:

$$
\left[\begin{array}{ll}
1 & \log \omega_{1} \\
\vdots & \\
1 & \log \omega_{n}
\end{array}\right]\left\{\begin{array}{c}
\log A \\
\alpha
\end{array}\right\}=\left\{\begin{array}{c}
\log k_{1} \\
\vdots \\
\log k_{n}
\end{array}\right\} \text {. }
$$

The pulsation vector is expressed in $\mathrm{rad} / \mathrm{s}$. 


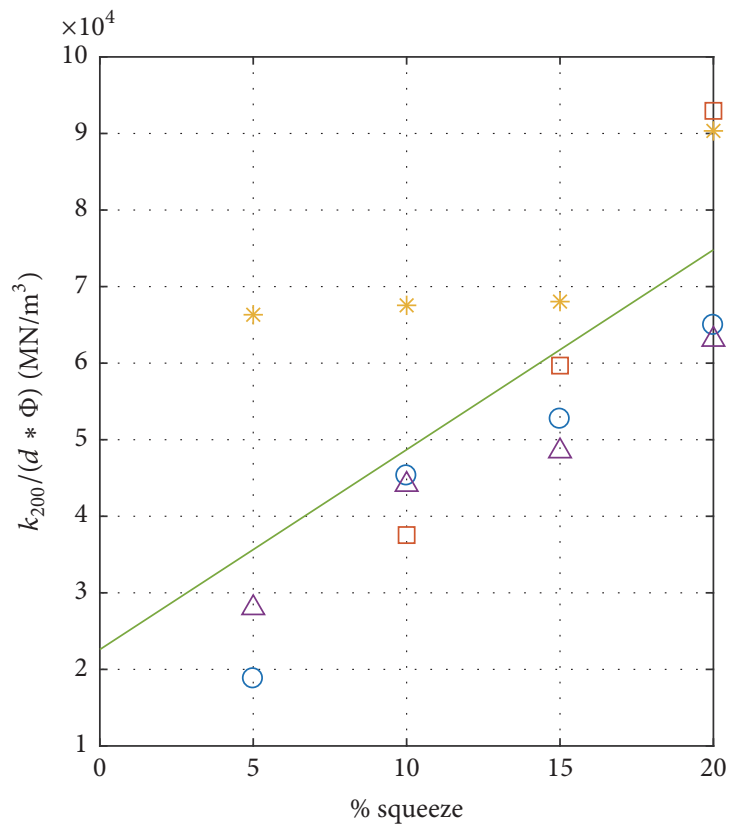

○ $d=11 \mathrm{~mm}, \phi=1.78 \mathrm{~mm}$

$\square \quad d=11 \mathrm{~mm}, \phi=2.62 \mathrm{~mm}$

* $d=41 \mathrm{~mm}, \phi=1.78 \mathrm{~mm}$

$\triangle d=41 \mathrm{~mm}, \phi=2.62 \mathrm{~mm}$ Interp.

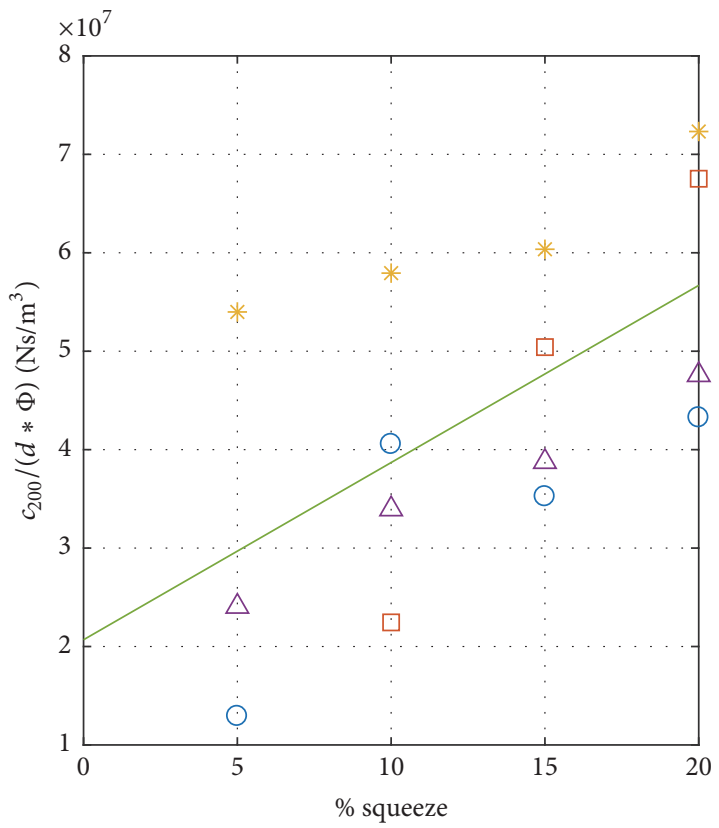

○ $d=11 \mathrm{~mm}, \phi=1.78 \mathrm{~mm}$

$\square \quad d=11 \mathrm{~mm}, \phi=2.62 \mathrm{~mm}$

* $d=41 \mathrm{~mm}, \phi=1.78 \mathrm{~mm}$ $\triangle d=41 \mathrm{~mm}, \phi=2.62 \mathrm{~mm}$ Interp.

FIGURE 12: $\bar{k}_{200}$ and $\bar{c}_{200}$ versus $S$ for Viton 75 .

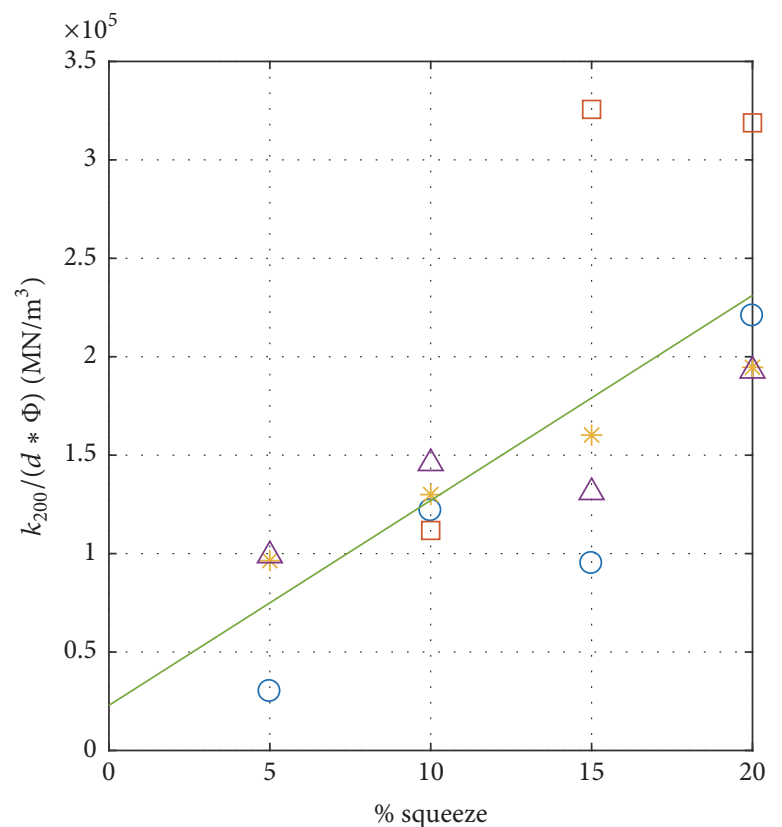

$\bigcirc \quad d=11 \mathrm{~mm}, \phi=1.78 \mathrm{~mm}$

$\square \quad d=11 \mathrm{~mm}, \phi=2.62 \mathrm{~mm}$

* $d=41 \mathrm{~mm}, \phi=1.78 \mathrm{~mm}$

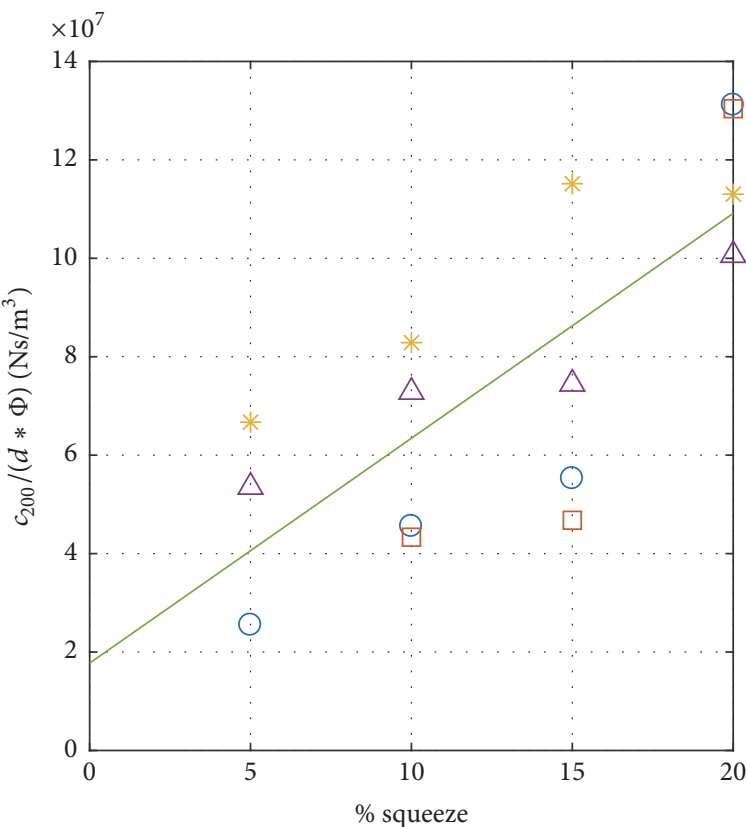

O $d=11 \mathrm{~mm}, \phi=1.78 \mathrm{~mm}$

$\square \quad d=11 \mathrm{~mm}, \phi=2.62 \mathrm{~mm}$

$\triangle d=41 \mathrm{~mm}, \phi=2.62 \mathrm{~mm}$ Interp.

FIgURE 13: $\bar{k}_{200}$ and $\bar{c}_{200}$ versus $S$ for Viton 90. 
Similar procedure was adopted for coefficients $B$ and $\beta$ :

$$
\left[\begin{array}{cc}
1 & \log \omega_{1} \\
\vdots & \\
1 & \log \omega_{n}
\end{array}\right]\left\{\begin{array}{c}
\log B \\
\beta
\end{array}\right\}=\left\{\begin{array}{c}
\log c_{1} \\
\vdots \\
\log c_{n}
\end{array}\right\} .
$$

\section{B. Extrapolating Coefficients}

Coefficients $C$ and $\gamma$ are calculated solving the following linear system by least squares procedure:

$$
\left[\begin{array}{ll}
1 & S_{1} \\
\vdots & \\
1 & S_{n}
\end{array}\right]\left\{\begin{array}{l}
C \\
\gamma
\end{array}\right\}=\left\{\begin{array}{c}
\bar{k}_{200,1} \\
\vdots \\
\bar{k}_{200, n}
\end{array}\right\} .
$$

The squeeze is expressed in percentage form.

Similar procedure was adopted for coefficients $D$ and $\delta$ :

$$
\left[\begin{array}{ll}
1 & S_{1} \\
\vdots & \\
1 & S_{n}
\end{array}\right]\left\{\begin{array}{l}
D \\
\delta
\end{array}\right\}=\left\{\begin{array}{c}
\bar{c}_{200,1} \\
\vdots \\
\bar{c}_{200, n}
\end{array}\right\} .
$$

\section{Conflicts of Interest}

The authors declare that they have no conflicts of interest.

\section{Acknowledgments}

The authors wish to acknowledge KU Leuven and Politecnico di Torino for the financial support to this work.

\section{References}

[1] J. Kerr, "The onset and cessation of half speed whirl in air lubricated self pressurized journal bearings," NEL Report No. 237, 1966.

[2] S. Yoshimoto, "Improvement of static characteristics of an aerostatic journal bearing using the elastic deformation of an Oring," Tribology International, vol. 20, no. 5, pp. 290-296, 1987.

[3] J. W. Powell and M. C. Tempest, "A study of high speed machines with rubber stabilized air bearings," ASME Journal of Lubrication Technology, vol. 90, pp. 701-708, 1968.

[4] Z. Kazimierski, "Stability threshold of the flexibly supported hybrid gas journal bearings," Journal of lubrication technology, vol. 101, pp. 451-457, 1979.

[5] D. A. Boffey and D. M. Desai, "An experimental investigation into the rubber-stabilization of an externally-pressurized airlubricated thrust bearing," ASME Journal of Lubrication Technology, vol. 102, pp. 65-70, 1980.

[6] S. Dousti, J. A. Kaplan, F. He, and P. E. Allaire, "Elastomer Orings as centering spring in squeeze film dampers: Application to turbochargers," in Proceedings of the ASME Turbo Expo 2013: Turbine Technical Conference and Exposition, GT 2013, June 2013.
[7] S. Dousti, T. W. Dimond, P. E. Allaire, and H. E. Wood, "Time transient analysis of horizontal rigid rotor supported with $\mathrm{O}$ ring sealed squeeze film damper," in Proceedings of the ASME 2013 International Mechanical Engineering Congress and Exposition, IMECE 2013, November 2013.

[8] K. Czołczyński and K. Marynowski, "Stability of symmetrical rotor supported in flexibly mounted, self-acting gas journal bearings," Wear, vol. 194, no. 1-2, pp. 190-197, 1996.

[9] T. Waumans, J. Peirs, F. Al-Bender, and D. Reynaerts, "Aerodynamic journal bearing with a flexible, damped support operating at 7.2 million DN," Journal of Micromechanics and Microengineering, vol. 21, no. 10, Article ID 104014, 2011.

[10] A. J. Smalley, M. S. Darlow, and R. K. Mehta, "The dynamic characteristics of O-rings," Journal of Mechanical Design, vol. 100, pp. 132-138, 1978.

[11] G. Belforte, F. Colombo, T. Raparelli, and V. Viktorov, "Highspeed rotor with air bearings mounted on flexible supports: Test bench and experimental results," Journal of Tribology, vol. 130, no. 2, pp. 1-7, 2008.

[12] R. M. Christensen, Theory of Viscoelasticity, Academic Press, New York, NY, USA, 1982.

[13] N. Akturk and R. Gohar, "Damping the vibrations of a rigid shaft supported by ball bearings by means of external elastomeric O-ring dampers," IMechE: J, Journal of Engineering Tribology, vol. 208, pp. 183-190, 1994.

[14] C. Zhi et al., "Finite element analysis of sealing characteristics of the rubber O-ring for a mechanical seal," Journal of Sichuan University: Engineering Science Edition, vol. 43, pp. 234-239, 2011.

[15] C. Han, H. Zhang, and J. Zhang, "Structural Design and Sealing Performance Analysis of Biomimetic Sealing Ring," Applied Bionics and Biomechanics, vol. 2015, Article ID 358417, 2015.

[16] Z. J. J. Gui, "Finite Element Analysis of Contact Pressure on Oring," Lubrication Engineering, vol. 2, p. 024, 2010.

[17] M. Darlow and E. Zorzi, "Mechanical Design Handbook for Elastomers," NASA Contractor Reports 3423, 1981.

[18] R. G. Wensel et al., "Friction and axial force/displacement characteristics of elastomer seals in water," ASLE paper, vol. 84-LC6A-1, 1984.

[19] I. Green and I. Etsion, "Pressure and squeeze effects on the dynamic characteristics of the elastomer o-rings under small reciprocating motion," ASME Journal of Tribology, vol. 108, pp. 439-445, 1986.

[20] A. Bormann and R. Gasch, "Damping and stiffness coefficients of elastomer rings and their optimised application in rotor dynamics: theoretical investigations and experimental validation," Australian Journal of Mechanical Engineering, vol. 1, pp. 91-101, 2004.

[21] F. Colombo, T. Raparelli, and V. Viktorov, "Externally pressurized gas bearings: A comparison between two supply holes configurations," Tribology International, vol. 42, no. 2, pp. $303-$ $310,2009$.

[22] F. Colombo, T. Raparelli, A. Trivella, and V. Viktorov, "Lumped parameters models of rectangular pneumatic pads: Static analysis," Precision Engineering, vol. 42, pp. 283-293, 2015.

[23] F. Colombo, M. Moradi, T. Raparelli, A. Trivella, and V. Viktorov, "Multiple holes rectangular gas thrust bearing: dynamic stiffness calculation with lumped parameters approach," in Advances in Italian Mechanism Science, vol. 47 of Mechanisms 
and Machine Science, pp. 421-429, Springer International Publishing, 2017.

[24] G. Belforte, F. Colombo, T. Raparelli, A. Trivella, and V. Viktorov, "Study of the static and dynamic performance of rectangular air pads by means of lumped parameters models," in Proceedings of the ASME 2012 11th Biennial Conference on Engineering Systems Design and Analysis, ESDA 2012, pp. 531537, July 2012. 


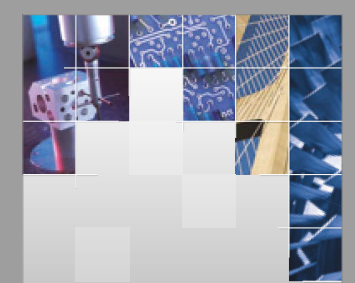

\section{Enfincering}
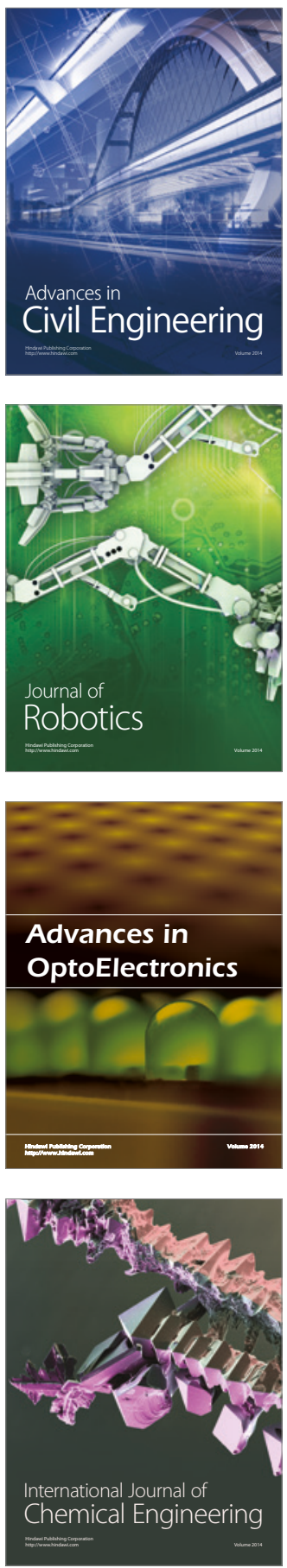

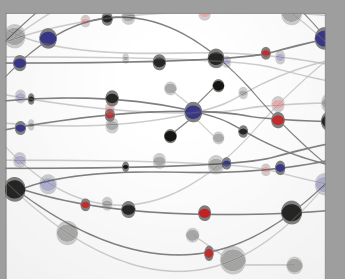

The Scientific World Journal

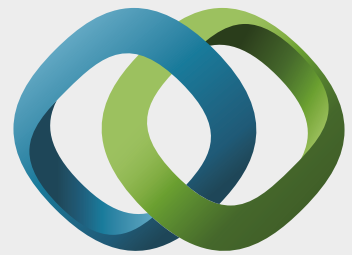

\section{Hindawi}

Submit your manuscripts at

https://www.hindawi.com
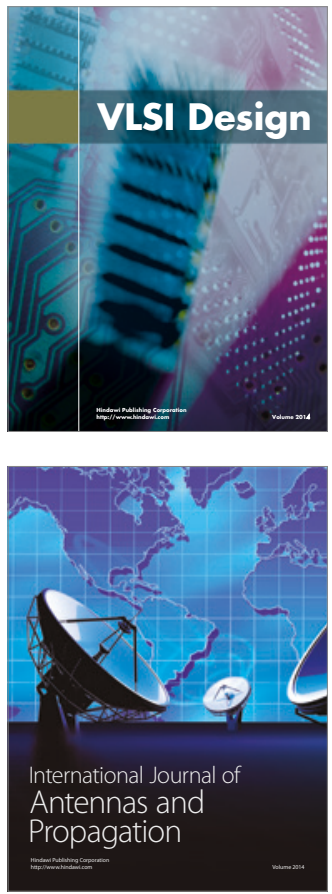

\section{Rotating}

Machinery
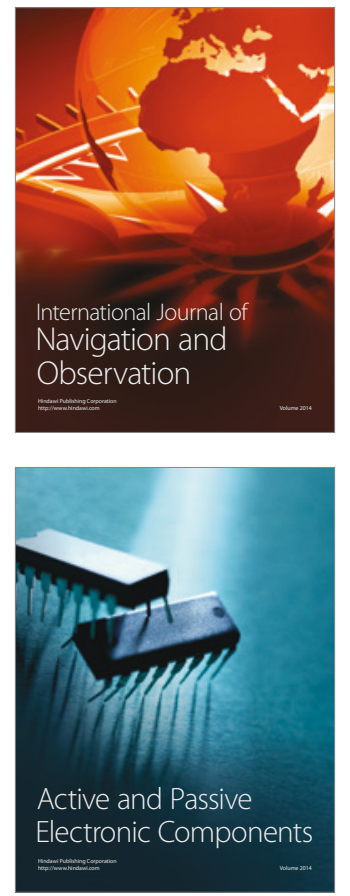
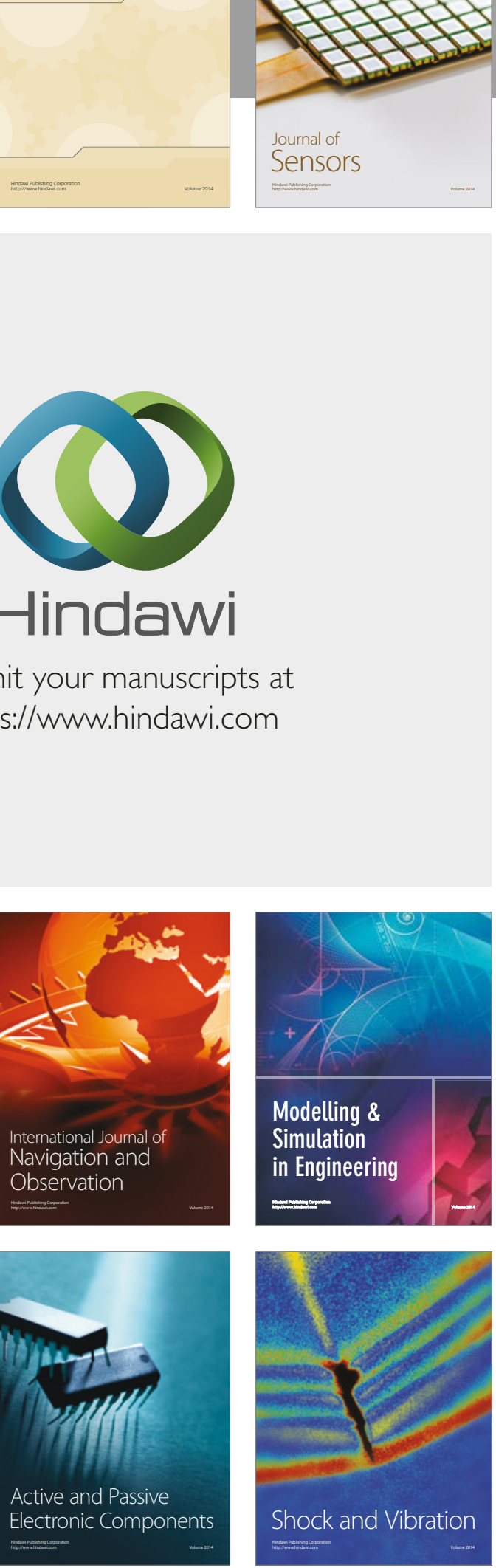
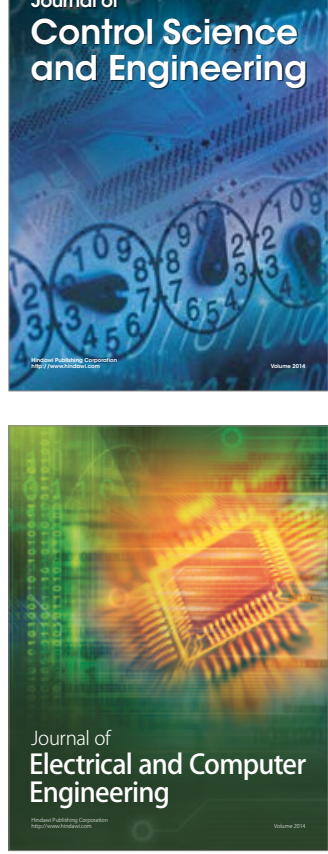

Distributed

Journal of

Control Science

and Engineering
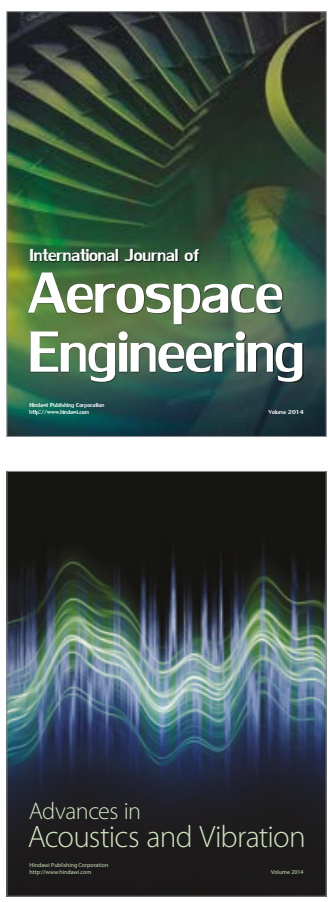

Sensor Networks 